\title{
Imagined Intergroup Contact and Common Ingroup Identity:
}

\section{An Integrative Approach}

\section{Loris Vezzali}

University of Modena and Reggio Emilia, Italy, E-mail: loris.vezzali@unimore.it

Sofia Stathi

University of Greenwich, United Kingdom, E-mail: S.Stathi@greenwich.ac.uk

\section{Richard J. Crisp}

University of Sheffield, United Kingdom, E-mail: r.crisp@ sheffield.ac.uk

\section{Dino Giovannini}

University of Modena and Reggio Emilia, Italy, E-mail: dino.giovannini@unimore.it

\section{Dora Capozza}

University of Padova, Italy, E-mail: dora.capozza@unipd.it

\author{
Samuel L. Gaertner
}

University of Delaware, USA, E-mail: gaertner@psych.udel.edu

Address correspondence to Loris Vezzali, University of Modena and Reggio Emilia, Department of Education and Humanities, viale Allegri 9, 42121, Reggio Emilia, Italy. Tel.: +390522 523006. Fax: +390522 523055. E-mail: loris.vezzali@unimore.it 
IMAGINED CONTACT AND COMMON INGROUP IDENTITY

\section{Acknowledgments}

We would like to thank Paola Spagnol and the other teachers for their help in the organization of the study. We are also grateful to the Institutes Frank and Giotto (Carpi) for allowing us to run the first study and collect data. Finally, we wish to thank Giulia Bergamini and Chaima Nadi, who helped with data collection and coding. 
IMAGINED CONTACT AND COMMON INGROUP IDENTITY

Imagined Intergroup Contact and Common Ingroup Identity: An Integrative Approach

Word count: 7,929 words 
IMAGINED CONTACT AND COMMON INGROUP IDENTITY

Running head: IMAGINED CONTACT AND COMMON INGROUP IDENTITY

Imagined Intergroup Contact and Common Ingroup Identity:

An Integrative Approach

\begin{abstract}
We conducted two studies involving two different age groups (elementary school children and adults) aimed at integrating imagined contact and common ingroup identity models. In the first study, Italian elementary school children were asked to imagine interacting with an unknown immigrant peer as members of a common group. Results revealed that common ingroup imagined contact, relative to a control condition, improved outgroup helping intentions assessed one week and two weeks after the intervention. In the second study, common ingroup imagined contact led Italian university students to display higher intentions to have contact with immigrants compared to control conditions. In conclusion, results from both studies demonstrate that imagining an intergroup interaction as members of the same group strengthens the effects of imagined contact. These findings point to the importance of combining the common ingroup identity model and the imagined contact theory in order to increase the potentiality of prejudice reduction interventions.
\end{abstract}

Keywords: imagined intergroup contact, common ingroup identity, intergroup relations, prejudice reduction, behavioral intentions. 
IMAGINED CONTACT AND COMMON INGROUP IDENTITY

Research over the past 60 years has convincingly demonstrated that positive contact between members of different groups is a powerful strategy to reduce prejudice (Hodson \& Hewstone, 2013). There is also evidence that positive contact is especially effective when it is structured so that ingroup and outgroup members perceive themselves as belonging to a common superordinate group, instead of completely separate and distinct groups (Gaertner \& Dovidio, 2000). However, intervention strategies based on direct intergroup contact can be anxiety arousing and difficult to implement due to practical constraints. A highly flexible and easily implemented indirect contact strategy which can overcome these difficulties and which has been successful at reducing prejudice is imagined contact. According to Crisp and collaborators (for reviews, see Crisp, Husnu, Meleady, Stathi, \& Turner, 2010; Crisp \& Turner, 2009, 2012; for a meta-analysis, see Miles \& Crisp, 2014), the mental simulation of positive intergroup contact is an effective way to improve relations between groups. In the two studies reported herein, we aim to explore the utility of integrating the common ingroup identity model (Gaertner \& Dovidio, 2000) with the imagined contact theory (Crisp \& Turner, 2009) on reducing intergroup bias. Our expectation is that common ingroup imagined contact, which combines imagined contact with principles derived from the common ingroup identity model, will have stronger effects than both standard imagined contact and classic control conditions used in imagined contact research. A further aim is to shed light on the processes underlying the effects of common ingroup imagined contact. Hypotheses will be tested both among young children (Study 1) and adults (Study 2), in order to examine the generalizability of the effects and the utility of the proposed approach for different age groups. An additional aim is to test the longevity of the effects, which will be assessed by 
IMAGINED CONTACT AND COMMON INGROUP IDENTITY

administering our measures to the children one and two weeks after the experimental intervention.

\section{Intergroup contact and common ingroup identity}

According to the common ingroup identity model (CIIM; Gaertner \& Dovidio, 2000), intergroup contact will be maximally effective at improving intergroup relations when group members recategorize the intergroup situation by perceiving themselves as members of a more inclusive common, superordinate category. Intergroup bias stemming from group distinctions would be reduced thereby, as former outgroup members are now accorded the status and the privileges of ingroup membership.

The CIIM has been supported by a number of experimental (e.g., Gaertner, Mann, Murrell, \& Dovidio, 1989), longitudinal (Levin, Sinclair, Sidanius, \& Van Laar, 2009), and cross-sectional (e.g., Gaertner, Rust, Dovidio, Bachman, \& Anastasio, 1994) studies. Support for the CIIM (Gaertner \& Dovidio, 2000) has also been obtained among young children (Guerra et al., 2010; Houlette et al., 2004). For instance, Guerra and collaborators (2010) conducted an experimental intervention with majority (European-Portuguese) and minority (African-Portuguese) elementary school children in Portugal. Results revealed that bias in resource allocations and competence ratings toward outgroup classmates was reduced when a superordinate identity (vs. a separate groups identity) was salient. Moreover, the positive effects of common identity on these evaluations generalized to the outgroup as a whole immediately following recategorization, and these effects persisted for at least three weeks.

However, despite their effectiveness, anti-bias interventions based on direct contact may be difficult to implement in real-world settings such as public schools (as in Study 1) because of practical constraints. We believe targeting prejudice in schools is 
IMAGINED CONTACT AND COMMON INGROUP IDENTITY

especially relevant, given that schools are increasingly multicultural and children spend most of their wakeful time in this setting. To this end imagined contact, compared to direct contact, requires less time, imposes fewer logistical problems involving space, resources and the potentially disruptive role of intergroup anxiety (Crisp \& Turner, 2012).In our research, we aim to combine the benefits of adopting a common ingroup identity with an indirect contact strategy that is practical to implement and extremely flexible: imagined contact.

\section{Imagined intergroup contact}

Imagined intergroup contact is defined as "the mental simulation of a social interaction with a member or members of an outgroup category" (Crisp \& Turner, 2009, p. 234). There is substantial evidence showing that imagined contact, especially when positively toned, has beneficial effects on intergroup relations. The recent meta-analysis by Miles and Crisp (2014) demonstrated that imagined contact has beneficial effects on intergroup attitudes, emotions, behavioral intentions and actual behavior, and these effects are consistent across different target-groups, age-groups and situational contexts.

Recent evidence shows that imagined contact improves intergroup relations not only among adults but also among children (Cameron, Rutland, Turner, HolmanNicolas, \& Powell, 2011; Stathi, Cameron, Hartley, \& Bradford, 2014; Vezzali, Capozza, Giovannini, \& Stathi, 2012; Vezzali, Capozza, Stathi, \& Giovannini, 2012). For instance, Vezzali, Capozza, Giovannini, et al. (2012) conducted an experimental intervention by asking Italian elementary school children to imagine, once a week for three consecutive weeks, a positive encounter with an unknown immigrant child in various social situations. Results revealed that, compared to a control condition, children in the imagined contact condition had more positive intentions to meet 
outgroup members and less implicit prejudice, as assessed one week after the last intervention session.

In the present research, where we propose an empowered form of imagined contact, we will also test whether the effects of an intervention combining principles from the imagined contact theory (Crisp \& Turner, 2012) and the CIIM (Gaertner \& Dovidio, 2000) can last after the end of the intervention. Specifically, in Study 1, a field intervention with children, we will assess dependent variables one week and two weeks after the end of the intervention. Assessing the longevity of effects is important in order to show that imagined contact can produce meaningful attitude change, thus contributing to the increasing canon of research supporting imagined contact effects, and directly addressing initial skepticism expressed about the utility of this strategy (Bigler \& Hughes, 2010).

The present research: Integrating the common ingroup identity model with

\section{the imagined contact theory}

An important function of imagined intergroup contact is that, ideally, it should prepare people for actual, direct contact with the outgroup. There is evidence that imagined contact increases confidence about future intergroup interactions (Stathi, Crisp, \& Hogg, 2011). Furthermore, it encourages positive behavioral intentions among both adults and children and its effects extend to overt behavior (Miles \& Crisp, 2014). In the present research we aim to extend previous research on imagined contact across two studies by exploring whether imagining a positive intergroup interaction under a common identity increases intentions to behave prosocially toward an outgroup member and intentions to have contact with individuals belonging to the outgroup. Specifically, we conducted one experimental intervention with elementary school children in which 
IMAGINED CONTACT AND COMMON INGROUP IDENTITY

we examined the effectiveness of common ingroup imagined contact on intentions to help outgroup members (Study 1), and one experiment with university students, evaluating the effects of common ingroup imagined contact on intentions to have faceto-face interactions with the outgroup (Study 2). The consideration of both child and adult samples will allow us to examine whether the proposed approach can be fruitfully used with different age groups. In both studies, participants in the common ingroup imagined contact condition were asked to imagine an interaction with an outgroup individual as members of the same superordinate group. In a second experimental condition, we included the standard imagined contact condition, where participants were asked to follow the typical imagined intergroup contact instructions (where participants are asked to mentally simulate a positive interaction with an unknown outgroup member) without mentioning a superordinate group. In a control condition, participants were asked to imagine an interaction with another person whose group membership was not specified.

Both studies were conducted in the context of Italy, with Italian participants; immigrants served as the target-outgroup. This choice is due to the fact that, in the context under examination, immigrants are an especially salient group. In fact, in the Emilia Romagna Region of Italy, where the research was conducted, the percentage of immigrants is higher compared to the average percentage in Italy (12.0\% vs. 8.1\%; National Institute of Statistics, 2013). Moreover, in this context, immigrants represent a stigmatized category both for adults (Giovannini \& Vezzali, 2012) and children (Vezzali, Giovannini, \& Capozza, 2012).

We predict that common ingroup imagined contact, compared with the control condition, will increase intergroup helping (Study 1) and contact intentions (Study 2). In 
other words, we expect that the effect of imagined contact is greater when participants imagined an intergroup interaction as members of the same group. This prediction is in line with studies based on direct contact. For instance, Gonzalez and Brown (2003; see also, e.g., Gaertner et al., 1989) found that attitudes toward the outgroup as a whole were more positive when participants interacted as members of the same group, compared to when the interaction, albeit positive, was framed in terms of respective group memberships (i.e., in the two-groups condition). Similarly, we expect that positive (imagined) contact will improve outgroup attitudes (i.e., behavioral intentions) compared to a control condition. However, as it happens for direct contact, imagining contact as members of the same category should improve attitudes to a greater extent because now outgroup members are accorded the privileges (and the evaluation) reserved to ingroup members.

In order to understand the processes that are potentially involved, we will test two mediators. In Study 1, where we will assess the duration of the effects of the intervention, we will test whether the improvement in intentions to help an unknown outgroup child (a measure of general behavioral intentions, conceptually similar to measures used to assess effects in previous imagined contact interventions) predicts specific intentions to help an outgroup child in a seemingly realistic situation. In Study 2 , in line with studies on direct contact, we will test whether the effect of common ingroup imagined contact on behavioral intentions actually depends on the fact that participants perceive themselves as members of a superordinate group (i.e., we test the mediator role of one-group representation).

Study 1 
We conducted an experimental intervention in a natural setting among elementary school children to test the effectiveness of imagining a positive intergroup encounter with an outgroup individual as members of the same group on intergroup helping. As we anticipated, we are interested in the duration of the effects of imagined contact. Previous studies showed that the effects of an imagined contact intervention can last up to one week among children (Stathi et al., 2014; Vezzali, Capozza, Giovannini, et al., 2012; Vezzali, Capozza, Stathi, et al., 2012; see also Vezzali, Crisp, Stathi, \& Giovannini, 2015, showing that the effects of imagined contact can last some months among adults). In this study, we examine the effects of common ingroup imagined contact one week and two weeks after the last intervention session. We decided to consider the time interval of one week in order to directly compare results with previous imagined contact studies conducted with children (e.g., Vezzali, Capozza, Stathi, et al., 2012). The dependent variable was also assessed after two weeks in order to evaluate whether common ingroup imagined contact effects would go beyond the time interval of one week used in previous imagined contact research conducted with a similar population. Considering a longer time span between first and second assessment would reduce the likelihood of observing an indirect effect from general to specific behavioral intentions.

The effects of the intervention are evaluated by considering two types of helping intentions. The first assessment (one week after the intervention) will focus on general helping intentions, i.e. general intentions to help an unspecified outgroup individual. This measure is conceptually similar to behavioral intention measures used in previous assessments (e.g., Vezzali, Capozza, Stathi, et al., 2012), asking for intentions to act positively toward unknown outgroup members without specifying the nature of the 


\section{IMAGINED CONTACT AND COMMON INGROUP IDENTITY}

situation. The second assessment, however, will focus on commitment to act prosocially toward an outgroup member in specific ways (e.g., how many hours are you able to help). We chose to focus on this measure of specific intentions to test whether the effects of common ingroup imagined contact increases the intention to help an outgroup member in specific ways when participants can believe that they realistically have the possibility of helping someone. Specifically, the hypothesis is that common ingroup imagined contact will have positive effects on helping intentions one week and two weeks after the intervention, and that general intentions act as mediator of the effect of common ingroup imagined contact on specific intentions to help the outgroup. The rationale is that general action plans (in our case, general helping intentions) may be realized in the form of specific intentions (such as committing to help an outgroup member who needs assistance to adjust to his/her new school). As such, general intentions that predict specific intentions can be considered as the most proximal predictor of actual behavior (Vallacher \& Wegner, 1987).

\section{Method}

\section{Participants, design and procedure}

Participants were 75 Italian third-, fourth- and fifth-graders. Three participants who did not fully understand the task were excluded ${ }^{1}$ leaving a final sample of 72 participants (29 males, 43 females). Age ranged from 7 years 9 months to 10 years 11 months; mean age was 9 years and 6 months. Children were randomly allocated to one of three experimental conditions: common ingroup imagined contact $(n=24)$, standard imagined contact $(n=26)$, control $(n=22)$. Specifically, within each class, children were randomly assigned to complete one out of three imagined situations, corresponding to the three experimental conditions. ${ }^{2}$ 
Children in all conditions took part in four intervention sessions, each lasting approximately 40 minutes. The intervention was conducted by the children's teachers (blind to the experimental hypotheses), who were instructed on how to explain and administer the task to children. Sessions took place during regular classes and were administered once each week for four consecutive weeks. In the common ingroup imagined contact condition, children were asked to imagine belonging to a common group with an immigrant child and cooperating with him/her while taking part together in a competition against other teams; to increase the positivity of the imagined interaction, children were also asked to imagine that they win this competition. Each week the contact scenario varied so as to avoid the subtyping of the imagined contact partner and to enhance generalizability. Specifically, each week children were instructed to imagine interacting with a different outgroup partner as members of a same group in a different situation, that is: a cooking competition at school (first session), a sport competition at the park (second session), a theatre play competition at school (third session), a learning competition at school (fourth session). The control condition was identical to the common ingroup identity imagined contact condition; the only difference was that the group membership of the contact partner was not mentioned, so children were likely to imagine being in a group with an ingroup member (for similar control conditions in the imagined contact literature, see e.g. Stathi \& Crisp, 2008, Study 2). We also included a standard imagined contact condition, which served as second control condition, in order to determine whether common ingroup imagined contact had stronger effects, compared to the control condition, than standard imagined contact. In this condition, over the four sessions, participants were instructed to imagine a positive contact with a different immigrant child across four different contact settings: 
IMAGINED CONTACT AND COMMON INGROUP IDENTITY

at school (first meeting), at the park (second meeting), in the neighborhood (third session), at the sport camp (fourth session) (a similar standard imagined contact procedure was used by Vezzali, Capozza, Giovannini, et al., 2012, and by Vezzali, Capozza, Stathi, et al., 2012).

With the aim of reinforcing the effect of the imagined task, in all conditions participants were given approximately 30 minutes to write a detailed description of the imagined encounter (Husnu \& Crisp, 2010) from a third-person perspective (Crisp \& Husnu, 2011) by keeping eyes closed while doing it (Husnu \& Crisp, 2011), all techniques that were found to enhance the effects of imagined contact (Crisp \& Turner, 2012). One week following the last (i.e., $4^{\text {th }}$ ) session, participants were asked to respond to a questionnaire containing the measure of general helping intentions. Two weeks after the last session, they were administered the specific helping intentions measure. The measures were administered by a researcher who was not present during the intervention sessions and was unaware of the experimental hypotheses.

\section{Measures}

Questionnaire

General helping intentions. To measure the intentions to help an unspecified outgroup member in a hypothetical situation, three items were used (e.g., "Think about an immigrant child who may have problems with writing an essay. Would you help him/her?"; see Vezzali, Cadamuro, Versari, Giovannini, \& Trifiletti, in press). A 5-point scale was used, ranging from 1 (definitely not) to 5 (definitely yes). Ratings were aggregated in a reliable index $($ alpha $=.81)$ : the higher the score, the stronger the intention to help outgroup children. 
IMAGINED CONTACT AND COMMON INGROUP IDENTITY

Specific helping intentions in a realistic situation. This measure was intended to provide children with a realistic (rather than hypothetical) situation where they could express their willingness to help an outgroup member in specific ways. Two weeks after the last session, a researcher met individually with each participant. The children were informed that an immigrant child was going to arrive soon in the school and, as this immigrant child may encounter difficulties integrating within the school, s/he may need a guide to be helped to adjust to the new context. Participants were then asked specifically, if they had sufficient time, how many afternoons (from zero up to a maximum of four) they will spend with the immigrant child and explain to him/her how things worked in the school.

\section{Results}

Means and standard deviations in the three conditions (common ingroup imagined contact, standard imagined contact, control) are presented in Table 1.

To test whether the intervention was effective in improving general helping intentions, we conducted a one-way ANOVA with experimental condition as the independent variable and general helping intentions as the dependent variable. A (marginal) main effect of condition was obtained, $F(2,69)=2.56, p<.09, \eta^{2}=0.07$. As predicted, participants displayed stronger general helping intentions in the common ingroup imagined contact $(M=4.69)$ than in the control $(M=4.17)$ condition, $t(44)=$ $2.18, p<.05$. However, although as predicted the mean for helping intentions in the standard imagined contact condition $(M=4.45)$ fell in between the mean in the control condition and the mean in the common ingroup imagined contact condition, differences between the standard imagined contact and the other two conditions were nonsignificant, $t \mathrm{~s}<1.40, p \mathrm{~s}>.16$ (Table 1$)$. 
IMAGINED CONTACT AND COMMON INGROUP IDENTITY

A similar ANOVA was conducted by entering specific intentions to help the outgroup in a realistic situation as the outcome variable, to test whether the effects found for helping intentions persisted two weeks after the intervention. A main effect of condition emerged, $F(2,69)=3.83, p<.05, \eta^{2} \mathrm{p}=0.10$. As predicted, participants agreed to help more in the common ingroup imagined contact $(M=3.17)$ than in the control condition $(M=2.27), t(44)=2.62, p<.05$. Closely replicating the linear trend observed for the general measure, the mean in the standard imagined contact condition $(M=2.83)$ fell in between means in the other two conditions, although these differences were again nonsignificant, $t \mathrm{~s}<1.66, p \mathrm{~s}>.10$ (Table 1$)$.

\section{Table 1}

We also tested whether general helping intentions mediated the effects of common ingroup imagined contact on specific helping intentions. As a predictor, given that we only obtained significant effects of common ingroup imagined contact vs. control, and because only common ingroup imagined contact (but not standard imagined contact) improved helping intentions vs. the control condition, we created a dummy variable where the common ingroup identity imagined contact condition was coded 1 and the control condition was coded 0 (thus excluding the standard imagined contact condition). This common ingroup imagined contact condition predicted both general helping intentions and specific helping intentions, $\beta \mathrm{s}=.31$ and $.37, p \mathrm{~s}<.05$, respectively. Second, when both experimental condition and general helping intentions were included in the regression equation, the path from general helping intentions to specific helping intentions was marginally significant, $\beta=.28 p<.06$, whereas the 
IMAGINED CONTACT AND COMMON INGROUP IDENTITY

direct path from experimental condition to specific helping intentions was reduced, $\beta=$ $.28, p<.06$. To test if the mediation effect was significant, bootstrapping analyses were conducted by using the SPSS macros provided by Preacher and Hayes (2008). Since 0 was excluded from the Bias Corrected and accelerated (BCa) 95\% confidence interval (ranging from .003 to .516), the indirect effect was significant, $p<.05$.

\section{Discussion}

In line with expectations, our results showed that, compared with the control condition, participants who mentally simulated positive encounters with an outgroup individual as members of the same group displayed more positive general intergroup helping intentions, assessed one week after the intervention, than those in the control condition. These effects were still significant two weeks following the intervention, when we assessed commitment to help an outgroup member in a realistic situation. Notably, however, the effectiveness of the standard imagined contact condition fell in between our "enhanced" common identity version and the control condition, rather than being significantly different from both. Thus, data from Study 1 do not permit an unequivocal conclusion that common ingroup imagined contact is more effective than standard imagined contact, although only the former condition was sufficiently powerful to improve helping intentions compared with the control condition.

There are several reasons that may account for why the standard imagined contact effect did not differ reliably from the control condition. First, in previous studies the intervention was conducted in small groups and was followed by group discussions (e.g., Vezzali, Capozza, Stathi, et al., 2012), whereas in this study children performed the imagined task during classes and did not discuss what they imagined. We chose to avoid group discussion because it would then have been especially difficult to 
disentangle its effects from those of common ingroup imagined contact and standard imagined contact. Moreover, since each class was split in to the different experimental groups, we would have had to conduct separate group discussions for each group. This would have caused practical problems and also risk that the participants would have shared their experiences with classmates, which would potentially contaminate each of the separate experimental conditions. To the extent that group discussion can strengthen and favor the effects of structured interventions (Meleady, Hopthrow, \& Crisp, 2013), the possibility that the intervention produced a strong effect was somewhat reduced in the present study. Second, in previous studies (e.g., Vezzali, Capozza, Giovannini, et al., 2012) children in the control condition did not engage in any imagined contact task, and were just administered the dependent measures; in this study, in the control condition, children imagined working cooperatively with another child, whose background was not specified. This condition is likely to have primed cooperation among participants, constituting in some way an intervention potentially affecting our dependent variables. This is especially important due to the close links between cooperation and helping intentions, as both of them imply a prosocial orientation.

Mediation analyses revealed that the effect of experimental condition on specific intentions to help an outgroup member in a realistic situation was (partially) mediated by general helping intentions. To the extent that specific action plans are an especially powerful predictor of real behavior (Vallacher \& Wegner, 1987), our findings suggest that improving general helping intentions may eventually translate in actual prosocial behavior. However, future research should measure actual behavior, rather than general and/or specific behavioral intentions. 
Despite the encouraging effects found for the proposed integrative common ingroup imagined contact intervention, it is important to obtain stronger evidence than that presented in Study 1. To this end, and to shed further light on the processes driving the effects of common ingroup imagined contact, we carried out a second study in a different context and with a different age group.

\section{Study 2}

We conducted a second experiment to replicate and extend previous findings by considering a different aged sample composed of university students. Considering a different age group would allow us to conclude that the effects found in Study 1 are not limited to children. In this study we also aimed to address some of the methodological issues that emerged in Study 1. First, in Study 1, participants in all conditions imagined a successful cooperative task, leaving open the possibility that the stronger effects found for the common ingroup imagined contact condition are due to increased attachment to the new ingroup following the winning of a competition (e.g., Worchel, Lind, \& Kaufman, 1975) rather than to salience of a one-group identity. To eliminate this concern, in Study 2 participants did not read explicit instructions regarding a successful outcome for the cooperative task. Second, in this study we included a second control condition commonly used in imagined contact research (e.g., Stathi \& Crisp, 2008, Study 2), where participants were asked to imagine a positive encounter with an individual stranger. Finding that outgroup attitudes are more positive in the common ingroup imagined contact condition compared to a classic control condition would increase confidence in our results. Third, previous studies on imagined contact conducted with both adults (e.g., Husnu \& Crisp, 2010) and children (e.g., Vezzali, Capozza, Giovannini, et al., 2012) used a measure of contact intentions as the dependent 
variable. In order to generalize results obtained in the first study and to compare the findings with previous research, in this study we focused on intentions to have future contact with the outgroup. Fourth, in the first study we examined general behavioral intentions as the mediator of the effects of the intervention on specific behavioral intentions, with the aim of testing whether and how a field intervention would influence the likelihood of helping a specific outgroup member. However, in order to more clearly test the hypothesized process underlying the effects of the empowered imagined contact, we included a measure of participants' one-group representation to serve as a potential mediator. Specifically, we aim to explore the extent to which this potential psychological mediator links the experimental conditions to participants' intentions to interact with outgroup members (Gaertner et al., 1989).

Hypotheses are the following:

H1: one-group perceptions and intentions to have future intergroup contact should be higher in the common ingroup imagined contact than in the standard imagined contact condition. This result would demonstrate that common ingroup imagined contact has stronger effects than standard imagined contact; H2: common ingroup imagined contact should have stronger effects compared with all the remaining conditions. If this is reliable it would further support the effectiveness of the strategy proposed;

H3: standard imagined contact should improve contact intentions compared with the two control conditions. If this contrast is reliable for the interaction measure, it would support research showing that imagined contact improves behavioral intentions concerning future interactions (e.g., Husnu \& Crisp, 2010). We would not expect this contrast to be reliable for the measure of the one-group 
representation. Indeed, one-group perceptions should increase when participants are asked to think to ingroup and outgroup as a common group. In contrast, there is no reason to expect that imagining a conversation with a member of a different group (without being asked to perceive themselves and the outgroup member as a single cognitive unit) will change participants' perceptions from two-groups to one-group;

H4: there should be no differences between the two control conditions, both for contact intentions and one-group representation, because common identity including ingroup and outgroup was not emphasized in either of the two conditions and it is unlikely that interacting with a generalized individual stranger would have an impact on intentions toward immigrants; H5: with respect to the processes involved, in line with literature on the CIIM (Gaertner \& Dovidio, 2000), we expect that one-group perceptions will mediate the effects of common ingroup imagined contact (vs. the other conditions) on future contact intentions.

\section{Method}

\section{Participants, design and procedure}

Participants were 105 Italian undergraduate students (15 males, 89 females, plus one where sex was not specified) at a northern Italian university. Mean age was 22.96 years $(S D=5.02)$. Participants were recruited individually in the university building or within classes by the researcher, and were randomly allocated to one of four experimental conditions: common ingroup imagined contact $(n=27)$, standard imagined contact $(n=26)$, control-common ingroup identity $(n=26)$, control-individual stranger $(n=26)$. 
IMAGINED CONTACT AND COMMON INGROUP IDENTITY

In the common ingroup imagined contact condition, participants were asked to take five minutes to imagine that the professor of one of their classes had divided them into several groups of two with the aim of preparing a presentation for the rest of the class, and that the best 2-person group would be rewarded with two additional credits toward their exam grade. In this condition, participants were informed that they formed a 2-person group with an unknown immigrant student. In the standard imagined contact condition, participants were asked to imagine meeting and having an interaction with an immigrant stranger for the first time with no mention of them working together as a group. The control-common ingroup identity condition was identical to the common ingroup imagined contact condition, except there was no mention of the group membership of their partner, allowing participants to assume their partner was an ingroup member (Stathi \& Crisp, 2008, Study 2). This control group served to exclude that any effects of the common ingroup imagined condition are simply due to cooperation, rather than to the creation of a common identity including an ingroup and an outgroup member. Similarly, the control-individual stranger condition was identical to the standard imagined contact condition, except that there was no reference to the partner's group membership. This is a typical control condition used in research on imagined contact. The purpose of including it was to exclude the possibility that the effects of standard imagined contact (and also of common ingroup imagined contact) are due to the mere simulation of a generalized social interaction, rather than to the simulation of a social interaction with an outgroup member. ${ }^{3}$

To increase the positivity of imagined contact, in all conditions, participants were also asked to imagine a positive interaction where they would discover new and unexpected things about the partner, and to describe their feelings and thoughts during 


\section{IMAGINED CONTACT AND COMMON INGROUP IDENTITY}

the interaction. Moreover, as in Study 1, in order to further reinforce the effect of the imagined task, participants were asked to imagine the contact situation from a thirdperson perspective, to keep their eyes closed while doing it, and to write down a detailed description of the imagined encounter (see Crisp \& Turner, 2012). Then, they were administered a questionnaire to complete before being debriefed and thanked for their participation.

\section{Measures}

For all items, a 7-point scale was used, ranging from 1 (not at all) to 7 (very much).

One-group perceptions. In line with research on the CIIM, one-group perceptions were assessed with a single item measure (e.g., Gaertner et al., 1989): "Do you perceive Italians and immigrants as members of a common group (residents of Italy)?”

Contact intentions. We used seven items, adapted from Ratcliff et al. (1999) and from Crisp and Husnu (2011), for example "Thinking about the next time you find yourself in a situation where you could interact with an immigrant, how likely do you think it is that you would strike up a conversation?"(alpha $=.93)$. Higher scores indicated a stronger desire to interact with immigrants in the future.

\section{Results}

Means and standard deviations in the four conditions are presented in Table 2.

Table 2 
IMAGINED CONTACT AND COMMON INGROUP IDENTITY

We conducted a one-way ANOVA for each of our dependent variables (onegroup perceptions, intentions to have future contact). Contrast analysis was used to examine our predictions, since it is recommended in hypothesis-driven research (Judd \& McClelland, 1989) and allows a clear and powerful test of specific and complex effects (Rosenthal, Rosnow, \& Rubin, 2000). First, we performed a contrast (C1) comparing the common ingroup imagined contact with the standard imagined contact condition, which allows us to test H1. Afterwards, we used Helmert contrasts to incrementally test our hypotheses. With the first Helmert contrast (C2), allowing us to test $\mathrm{H} 2$, we compared common ingroup imagined contact with the three remaining conditions. C3, used to test $\mathrm{H} 3$, compared standard imagined contact (with an immigrant) with the two control conditions involving interacting with a stranger with group identity unspecified. With $\mathrm{C} 4$ we tested $\mathrm{H} 4$ by examining eventual differences between the controlindividual stranger and the control-common ingroup identity condition. The contrasts used to test predictions are specified in Table 3.

Table 3

When using intentions for future interactions as the dependent variable, the main effect of condition was significant, $F(3,101)=9.34, p<.001, \eta^{2}{ }_{p}=0.22$. Consistent with $\mathrm{H} 1, \mathrm{C} 1$ (common ingroup imagined contact vs. standard imagined contact) was significant, $t=2.10, p<.05$. This indicates that common ingroup imagined contact is more effective than standard imagined contact in improving intentions to have future intergroup contact. Thus, it seems that our enhanced imagined contact manipulation has additional benefits compared to the standard imagined contact task. C2 (common 
ingroup identity with an immigrant vs. the other conditions) was significant, providing evidence for the effectiveness of common ingroup imagined contact in fostering the willingness to initiate contact with outgroup members, $t=4.52, p<.001$. Thus, as hypothesized in $\mathrm{H} 2$, common ingroup imagined contact proved to be more effective in improving contact intentions compared with all the other conditions considered together. Replicating the established role of standard imagined contact with an outgroup member in eliciting positive behavioral intentions (e.g., Husnu \& Crisp, 2010), C3 (standard imagined contact with an immigrant vs. control-individual stranger, i.e. with no mention of immigrant status of the partner, and control-common ingroup identity, i.e., with no mention of partner's immigrant status) was significant, $t=2.70, p<.01$. This result supports $\mathrm{H} 3$ and gives additional confidence in the results, as it shows that also the classic imagined contact manipulation acted toward improving behavioral intentions. Finally, as expected, C4 (control-individual stranger, i.e. without mention of partner's immigrant status vs. control-common ingroup identity, i.e. without mention of partner's immigrant status) was nonsignificant, $t<1$. This was expected (see H4), since neither of the two control conditions, which did not mention an intergroup encounter, was supposed to have beneficial effect on intergroup behavioral intentions.

The main effect of condition was also reliable when considering one-group perceptions as the dependent variable, $F(3,101)=5.82, p=.001, \eta_{\mathrm{p}}^{2}=0.15$. In line with expectations, $\mathrm{C} 1$ (common ingroup imagined contact vs. standard imagined contact) was significant, $t=2.21, p<.05$. This result, consistent with $\mathrm{H} 1$, allows us to conclude that imagining an interaction with an outgroup individual as members of the same group, compared to when the imagined intergroup interaction does not explicitly mention a common belonging, fosters the perception that ingroup and outgroup are part 


\section{IMAGINED CONTACT AND COMMON INGROUP IDENTITY}

of the same group (at least, it does so more strongly than when the belonging to a superordinate group is not explicitly mentioned in the instructions, that is, than in the standard imagined contact condition). C2 (common ingroup identity vs. the other conditions) was significant, $t=3.44, p=.001$. Thus, it seems that, as predicted in $\mathrm{H} 2$, common ingroup imagined contact is more effective in fostering the perception to belong to a common group that includes ingroup and outgroup, compared with the other conditions. Moreover, in line with H3,C3 (standard imagined contact vs. controlindividual stranger and control-common ingroup identity) was nonsignificant, indicating that imagined contact per se does not affect the one-group representation, $t=1.01$. $p=$ .31. Thus, simply asking to imagine a positive intergroup interaction does not induce people to feel that they belong to a common group including both ingroup and outgroup members. Contrary to $\mathrm{H} 4$, however, $\mathrm{C} 4$ (control-individual stranger vs. control-common ingroup identity) was significant, $t=2.14, p<.05$, revealing that one-group perceptions were higher in the control-individual stranger than in the control-common ingroup condition.

We then tested H5, by examining whether one-group perceptions mediate the effect of common ingroup imagined contact on intentions to have future contact. First, C2 (common ingroup identity vs. the other conditions), used as predictor variable, was significantly associated with both one-group perceptions and future contact intentions, $\beta \mathrm{s}=.32$ and $.40, p \mathrm{~s} \leq .001$, respectively. Second, when both experimental condition and one-group perceptions were entered as predictors, the path from one-group perceptions to contact intentions was significant, $\beta=.24, p<.05$, whereas the direct path from experimental condition to contact intentions was reduced, $\beta=.32, p=.001$. The 
IMAGINED CONTACT AND COMMON INGROUP IDENTITY

(partial) mediation effect was significant, as indicated by the fact that the $\mathrm{BCa} 95 \%$ bootstrapped confidence interval, ranging from .012 to .132 , excluded 0 .

\section{Discussion}

In this study we provided further evidence for the benefits that imagining a positive intergroup interaction as members of a common group has on intentions to have contact with the outgroup. In particular, intentions to have future contact were more positive in the common ingroup imagined contact than in the other conditions. Notably, supporting the view that common ingroup imagined contact has additional benefits compared with standard imagined contact, future contact intentions were more positive in the former than in the latter condition. Replicating previous research on imagined contact, participants displayed more positive contact intentions in the standard imagined contact than in the two control conditions.

It should be noted that in the standard imagined contact condition (as well as in the other conditions), consistent with Study 1, we used a series of task variants that have been shown to be crucial factors in order to strengthen the effects of imagined contact, such as closing eyes during the imagined task and imagining the situation from a thirdperson perspective. Critically, contact intentions were still higher in the common ingroup imagined contact compared to this very elaborated standard imagined contact condition. This represents a robust test for our hypotheses and provides strong evidence for the positive role of imagined contact that is structured in a way that promotes a common ingroup identity.

Results also showed that, in line with research on the CIIM (Gaertner \& Dovidio, 2000), the improvement in intentions to have contact following common 
IMAGINED CONTACT AND COMMON INGROUP IDENTITY

ingroup imagined contact was (partially) explained by the increase in the perception that ingroup and outgroup members belong to a common group.

An unexpected finding was that one-group perceptions (specifically mentioning immigrants) were higher in the control-individual stranger than in the control-common ingroup condition. A possible explanation is that imagining to be in a common group with someone who is likely to be an ingroup member (e.g., Stathi \& Crisp, 2008, Study 2; Turner \& West, 2012) may have activated the ingroup category, i.e., Italians, excluding immigrants from the larger category of inhabitants of Italy, compared to when a common group was not made salient (in the control-individual stranger condition).

\section{General discussion}

We conducted one experimental intervention with elementary school children (Study 1) and one experiment with university students (Study 2) to demonstrate that enhancing an imagined intergroup encounter with the salience of a common ingroup identity is an especially effective way to improve intergroup relations, relative to just imagining an intergroup encounter. Additional aims were to investigate the processes driving the effects of common ingroup imagined contact and the longevity of effects of an experimental intervention.

In general, results supported our predictions, showing the benefits of adopting a superordinate identity during the mental simulation of contact. In Study 1, participants who mentally simulated positive encounters with an outgroup individual as members of the same group displayed more positive general helping intentions and commitment to act prosocially toward a specific outgroup member, assessed respectively one and two weeks following the intervention, than those in a control condition. Moreover, the effect 
IMAGINED CONTACT AND COMMON INGROUP IDENTITY

of common ingroup imagined contact on commitment to help was mediated by general helping intentions. Although the predicted linear trend was apparent, the means in the common ingroup imagined contact did not differ from those in the standard imagined contact condition (for a detailed explanation of the possible reasons concerning the absence of these effects, see Discussion of Study 1).

Study 2, however, where we considered a different-aged sample (i.e., university students), a different type of intergroup intention (i.e., intention to have contact with the outgroup in the future) and a further control condition typically used in research on imagined contact (e.g., Stathi \& Crisp, 2008, Study 2), revealed that common ingroup imagined contact had additional beneficial effects compared with standard imagined contact.

Theoretically, these findings extend previous research in several ways. First, they integrate two effective prejudice reduction models, that is, the common ingroup identity model (Gaertner \& Dovidio, 2000) and the imagined contact theory (Crisp \& Turner, 2012), by demonstrating the importance of enhancing the salience of a common ingroup identity during imagined contact both with adults and children. Despite the impressive amount of studies that demonstrate the effectiveness of these two approaches, evidence supporting their basic predictions within educational settings is scarce (for exceptions, see e.g. Guerra et al., 2010; Vezzali, Capozza, Giovannini, et al., 2012). Second, our research contributes to the literature with regard to the underlying processes of the effects of imagined contact. In Study 2, in line with the literature on the CIIM (Gaertner \& Dovidio, 2000), the effects of common ingroup imagined contact were mediated by a one-group representation. Third, they show that the effects of an intervention involving common ingroup imagined contact can last at least two weeks. 
We note that the measure of commitment to help an outgroup member used in Study 1 represented a precise intention that, as such, is highly likely to be associated with actual behavior. In fact, children were not expressing a simple desire to eventually help outgroup members by donating some of their free time; rather, they believed that they were actually deciding to spend these afternoons with an unknown immigrant child. The fact that results for this measure were obtained in a naturalistic context with children two weeks after the intervention is also noteworthy and adds to the importance of our findings.

We believe that our results are especially noteworthy given the rigorous design that included a number of very relevant control conditions. Indeed, in both studies, we used for the standard imagined contact condition (as well as for the common ingroup identity condition) a series of task variants identified by research to make the effects of imagined contact more powerful. This was the first test of creating such elaborate imagined contact conditions based on extensive findings from previous research. The fact that in Study 2 common ingroup imagined contact had a stronger effect than an already powerful form of standard imagined contact represents a strong confirmation for our hypothesis. We note that the same task variants were also used in the control condition, so as to exclude them as a possible source driving differences among conditions.

An important practical implication of this research relates to the fact that imagined contact tasks can easily be administered during classes or as homework as part of school curriculum. Imagined contact could create the basis for reciprocal trust between the ingroup and the outgroup and, ultimately, facilitate cross-group friendships. Notably, additional analyses revealed that, in Study 1, school grade did not moderate 


\section{IMAGINED CONTACT AND COMMON INGROUP IDENTITY}

the results obtained. Thus, in line with previous studies, imagined contact proved to be an effective strategy to improve intergroup relations among children from 8 to 10 years of age. Moreover, the present findings help overcome some of the reasons for skepticism on imagined contact posed by Bigler and Hughes (2010). For instance, Study 1 demonstrated that imagined contact can be used in multiple-session interventions and that interventions based on imagined contact can have long-lasting effects of at least two weeks. Moreover, as researchers involved in the assessment of intervention effects were not the same who administered the intervention, the possibility that effects were due to demand characteristics is unlikely. As advocated by Crisp et al. (2010), imagined contact interventions in educational contexts are complementary to other prejudice reduction strategies and should be used in combination with alternative types of interventions based, for instance, on extended contact (Cameron \& Rutland, 2006; Vezzali, Stathi, Giovannini, Capozza, \& Trifiletti, 2015, Study 1) and, whenever possible, direct contact (Turner, Hewstone, \& Voci, 2007).

We acknowledge some limitations, related to underlying processes unique as well as shared by both the imagined contact and the common ingroup identity perspectives that we did not address. For instance, common ingroup imagined contact could work both via vividness of the imagined scenario (a process unique to the imagined contact perspective; Husnu \& Crisp, 2010) and increased closeness toward former outgroup members (a process related to the common ingroup identity perspective; see Gaertner \& Dovidio, 2000). In turn, increased vividness and psychological closeness could lead to reduced intergroup anxiety and empathy, which should stem both from imagined contact and common ingroup identity, in turn leading to more positive outgroup attitudes. Indeed, imagining contact should arise less anxiety 


\section{IMAGINED CONTACT AND COMMON INGROUP IDENTITY}

(Turner, Crisp, \& Lambert, 2007, Study 3) than actual contact, because individuals should be less concerned about imagining a cross-group interaction rather than actively taking part in it (e.g., Turner, Crisp, et al., 2007, Study 3). Similarly, imagined contact was shown to increase empathic feelings for the outgroup (e.g., Kuchenbrandt, Eyssel, $\&$ Seidel, 2013). Moreover, the activation of a common ingroup identity should lower intergroup anxiety (e.g., Riek, Mania, Gaertner, McDonald, \& Lamoreaux, 2010, Study 1) and increase intergroup empathy (e.g., Capozza, Trifiletti, Vezzali, \& Favara, 2013, Study 2), because now former outgroup members benefit from the fact that they are now accorded the ingroup status. Future research should test these possibilities and examine more closely the processes explaining the combined perspectives of imagined contact and common ingroup identity.

In conclusion, the present research shows that integrating the basic principles of imagined contact (Crisp et al., 2010) and the common ingroup identity model (Gaertner \& Dovidio, 2000) can improve intergroup relations. 


\section{Footnotes}

1. These participants were not able to provide a written description of the imagined encounter, which serves as a manipulation check that participants were willing and able to produce a contact scenario as instructed (Crisp \& Turner, 2012). When including these participants in the analyses, the results remain mostly similar.

2. Assigning children to the three conditions in each class was possible because instructions were identical for the three conditions. Specifically, in all conditions children were asked to read carefully the instructions received, which detailed the situation to imagine, and then to write down what they had just imagined. The specific content of the imagined task in each condition was not specified by the teacher, in order to avoid any possible confounding. Furthermore, the fact that, in contrast with previous studies (e.g., Vezzali, Capozza, Stathi, et al., 2012), children did not engage in any discussions with the teacher after the experimental sessions helped to avoid discussions concerning the three different tasks assigned to children in each class.

3. We conducted a post-study to ensure that participants in the control-common ingroup identity and control-individual stranger conditions actually imagined an intragroup interaction. Ten Italian university students were given the instructions used in the control-common ingroup identity and control-individual stranger conditions (five students for each condition). After the imagined task, instead of completing the final questionnaire, they were asked whether the contact partner they imagined was an Italian or an immigrant. All participants imagined to have contact with an Italian partner. On the basis of these results, we are confident that 


\section{IMAGINED CONTACT AND COMMON INGROUP IDENTITY}

participants in the control-common ingroup identity and control-individual stranger conditions imagined an intragroup, rather than an intergroup, situation. 


\section{References}

Bigler, R. S., \& Hughes, J. M. (2010). Reasons for skepticism about the efficacy of similated social contact interventions. American Psychologist, 65, 132-133.

Cameron, L., \& Rutland, A. (2006). Extended contact through story reading in school: Reducing children's prejudice toward the disabled. Journal of Social Issues, 62, 469488.

Cameron, L., Rutland, A., Turner, R. N., Holman-Nicolas, R., \& Powell, C. (2011). "Changing attitudes with a little imagination": Imagined contact effects on young children's intergroup bias. Anales de Psicologia, 27, 708-717.

Capozza, D., Trifiletti, E., Vezzali, L., \& Favara, I. (2013). Can contact improve humanity attributions? International Journal of Psychology, 48, 527-541

Crisp, R. J., \& Husnu, S. (2011). Attributional processes underlying imagined contact effects. Group Processes and Intergroup Relations, 14, 275-287.

Crisp, R. J., Husnu, S., Meleady, R., Stathi, S., \& Turner, R. N. (2010). From imagery to intention: A dual-route model of imagined contact effects. European Review of Social Psychology, 21, 188-236.

Crisp, R. J., \& Turner, R. N. (2009). Can imagined contact interactions produce positive perceptions? Reducing prejudice through simulated social contact. American Psychologist, 64, 231-240.

Crisp, R. J. \& Turner, R. N. (2012). The imagined contact hypothesis. In J. Olson \& M. P. Zanna (Eds.), Advances in Experimental Social Psychology (vol. 46, pp. 125-182). Orlando, FL: Academic Press. 
IMAGINED CONTACT AND COMMON INGROUP IDENTITY

Fishbein, M., \& Ajzen, I. (1974). Attitudes towards objects as predictors of single and multiple behavioural criteria. Psychological Review, 8, 59-74.

Gaertner, S. L., \& Dovidio, J. F. (2000). Reducing intergroup bias: The common ingroup identity model. Philadelphia, PA: Psychology Press.

Gaertner, S., Mann, J., Murrell, A., \& Dovidio, J. F. (1989). Reducing intergroup bias: The benefits of recategorization. Journal of Personality and Social Psychology, 57, 239-249.

Gaertner, S. L., Rust, Dovidio, J. F., Bachman, B. A., \& Anastasio, P. A. (1994). The contact hypothesis: The role of a common ingroup identity on reducing intergroup bias. Small Group Research, 25, 224-249.

Giovannini, D., \& Vezzali, L. (a cura di) (2012). Lavorare insieme. Imprese cooperative, climi lavorativi e immigrazione. Milano: Edizioni Guerini e Associati.

Guerra, R., Rebelo, M., Monteiro, M. B., Riek, B. M., Mania, E. W., Gaertner, S. L., \& Dovidio, J. F. (2010). How should intergroup contact be structured to reduce bias among majority and minority group children? Group Processes and Intergroup Relations, 13, 445-460.

Hodson, G., \& Hewstone, M. (Eds.) (2013). Advances in intergroup contact. New York: Psychology press.

Houlette, M. A., Gaertner, S. L., Johnson, K. M., Banker, B. S., Riek, B. M., \& Dovidio, J. F. (2004). Developing a more inclusive social identity: An elementary school intervention. Journal of Social Issues, 60, 35-55.

Husnu, S., \& Crisp, R. J. (2010). Elaboration enhances the imagined contact effect. Journal of Experimental Social Psychology, 46, 943-950. 
IMAGINED CONTACT AND COMMON INGROUP IDENTITY

Husnu, S., \& Crisp, R. J. (2011). Enhancing the imagined contact effect. Journal of Social Psychology, 151, 113-116.

Judd, C. M., \& McClelland, G. H. (1989). Data analysis: A model comparison approach. San Diego, CA: Harcourt, Brace, Jovanovic.

Kuchenbrandt, D., Eyssel, F., \& Seidel, S. K. (2013). Cooperation makes it happen: Imagined intergroup cooperation enhances the positive effects of imagined contact. Group Processes and Intergroup Relations, 16, 635-647.

Levin, S., Sinclair, S., Sidanius, J., \& Van Laar, C. (2009). Ethnic and university identities across the college years: A common in-group identity perspective. Journal of Social Issues, 65, 287-306.

Meleady, R., Hopthrow, T., \& Crisp, R. J. (2013). The group discussion effect: Integrative processes and suggestions for implementation. Personality and Social Psychology Review, 17, 56-71.

Miles, E., \& Crisp, R. J. (2014). A meta-analytic test of the imagined contact hypothesis. Group Processes and Intergroup Relations, 17, 3-26.

National Institute of Statistic (2013). Demography in numbers. Retrieved $9^{\text {th }}$ september 2013 from http://demo.istat.it

Preacher, K. J., \& Hayes, A. F. (2008). Asymptotic and resampling strategies for assessing and comparing indirect effects in multiple mediator models. Behavior Research Methods, 40, 879-881.

Ratcliff, C. D., Czuchry, M., Scarberry, N. C., Thomas, J. C., Dansereau, D. F., \& Lord, C. G. (1999). Effects of directed thinking on intentions to engage in beneficial activities: Actions versus reasons. Journal of Applied Social Psychology, 29, 9941009. 
Riek, B. M., Mania, E. W., Gaertner, S. L., McDonald, S. A., \& Lamoreaux, M. J. (2010). Does a common identity reduce intergroup threat? Group Processes and Intergroup Relations, 13, 403-423.

Rosenthal, R., Rosnow, R. L., \& Rubin, D. B. (2000). Contrasts and effect sizes in behavioral research: A correlational approach. New York, NY: Cambridge University Press.

Stathi, S., Cameron, L., Hartley, B., \& Bradford, S. (2014). Imagined contact as a prejudice-reduction intervention in schools: The underlying role of similarity and attitudes. Journal of Applied Social Psychology, 44, 536-546.

Stathi, S., \& Crisp, R. J. (2008). Imagining intergroup contact promotes projection to outgroups. Journal of Experimental Social Psychology, 44, 943-957.

Stathi, S., Crisp, R. J., \& Hogg, M. A. (2011). Imagining intergroup contact enables member-to-group generalization. Group Dynamics, 15, 275-284.

Turner, R. N., Crisp, R. J., \& Lambert, E. (2007). Imagining intergroup contact can improve intergroup attitudes. Group Processes and Intergroup Relations, 10, 427441.

Turner, R. N., Hewstone, M., \& Voci, A. (2007). Reducing explicit and implicit outgroup prejudice via direct and extended contact: The mediating role of selfdisclosure and intergroup anxiety. Journal of Personality and Social Psychology, 93, 369-388.

Turner, R. N., \& West, K. (2012). Behavioural consequences of imagining intergroup contact with stigmatized outgroups. Group Processes and Intergroup Relations, 15, 193-202. 
Vallacher, R. R., \& Wegner, D. M. (1987). What do people think they are doing? Action identification and human behavior. Psychological Review, 94, 3-15.

Vezzali, L., Cadamuro, A., Versari, A., \& Giovannini, D. (in press). Feeling like a group after a natural disaster: Common ingroup identity and relations with outgroup victims among majority and minority young children. British Journal of Social Psychology.

Vezzali, L., Capozza, D., Giovannini, D., \& Stathi, S. (2012). Improving explicit and implicit intergroup attitudes using imagined contact: An experimental intervention with elementary school children. Group Processes and Intergroup Relations, 15, 203-212.

Vezzali, L., Capozza, D., Stathi, S., \& Giovannini, D. (2012). Increasing outgroup trust, reducing infrahumanization, and enhancing future contact intentions via imagined intergroup contact. Journal of Experimental Social Psychology, 48, 437-440.

Vezzali, L., Crisp, R. J., Stathi, S., \& Giovannini, D. (2015). Imagined intergroup contact facilitates intercultural communication for college students on academic exchange programs. Group Processes and Intergroup Relations, 18, 66-75.

Vezzali, L., Giovannini, D., \& Capozza, D. (2012). Social antecedents of children's implicit prejudice: Direct contact, exteded contact, explicit and implicit teachers' prejudice. European Journal of Developmental Psychology, 9, 569-581

Vezzali, L., Stathi, S., Giovannini, D., Capozza, D., \& Trifiletti, E. (2015). The greatest magic of Harry Potter: Reducing prejudice. Journal of Applied Social Psychology, $45,105-121$. 


\section{IMAGINED CONTACT AND COMMON INGROUP IDENTITY}

Worchel, S., Lind, E. A., \& Kaufman, K. H. (1975). Evaluations of group products as a function of expectations of group longevity, outcome of competition, and publicity of evaluations. Journal of Personality and Social Psychology, 31, 1089-1097. 
IMAGINED CONTACT AND COMMON INGROUP IDENTITY

\section{Tables}

Table 1. Means for general and specific intergroup helping intentions in the three experimental conditions (standard deviations are reported in parentheses) (Study 1).

\begin{tabular}{lccc}
\hline Measure & $\begin{array}{c}\text { Common } \\
\text { ingroup } \\
\text { imagined } \\
\text { contact }\end{array}$ & $\begin{array}{c}\text { Condition } \\
\text { Standard } \\
\text { imagined } \\
\text { contact }\end{array}$ & Control \\
\hline General helping intentions & $\begin{array}{c}\text { 4.69a } \\
(0.47)\end{array}$ & $\begin{array}{l}4.45 \mathrm{ab} \\
(0.74)\end{array}$ & $4.17 \mathrm{~b}$ \\
Specific helping intentions in a & $3.17 \mathrm{a}$ & $2.83 \mathrm{ab}$ & $(1.08)$ \\
realistic situation & $(1.01)$ & $(1.01)$ & $2.27 \mathrm{~b}$ \\
& & & $(1.32)$
\end{tabular}

Note. The scale ranges from 1 to 5 for the measure of general helping intentions, and from 0 to 4 for the measure of specific helping intentions. Different letters on the same row indicate that the means are significantly different, $p<.05$. 
IMAGINED CONTACT AND COMMON INGROUP IDENTITY

Table 2. Means for intergroup contact intentions and one-group perceptions in the four experimental conditions (standard deviations are reported in parentheses) (Study 2).

\begin{tabular}{lcccc}
\hline & \multicolumn{2}{c}{ Condition } \\
Measure & $\begin{array}{c}\text { Common ingroup } \\
\text { imagined contact }\end{array}$ & $\begin{array}{c}\text { Standard } \\
\text { imagined contact }\end{array}$ & $\begin{array}{c}\text { Control-common } \\
\text { ingroup identity }\end{array}$ & $\begin{array}{c}\text { Control- } \\
\text { individual } \\
\text { stranger }\end{array}$ \\
\hline $\begin{array}{l}\text { Intergroup } \\
\text { contact }\end{array}$ & $5.29 \mathrm{a}$ & $4.63 \mathrm{~b}$ & $3.80 \mathrm{c}$ & $3.96 \mathrm{c}$ \\
$\begin{array}{l}\text { intentions } \\
\begin{array}{l}\text { One-group } \\
\text { perceptions }\end{array}\end{array}$ & $(1.06)$ & $(1.22)$ & $(1.14)$ & $(1.19)$ \\
\hline
\end{tabular}

Note. For both measures, the response scale ranges from 1 to 7 . Different letters on the same row indicate that the means are significantly different, $p<.05$. 
IMAGINED CONTACT AND COMMON INGROUP IDENTITY

Table 3. Contrasts tested (Study 2).

\begin{tabular}{|c|c|c|c|c|}
\hline \multirow[b]{2}{*}{ Contrast } & \multicolumn{4}{|c|}{ Condition } \\
\hline & $\begin{array}{l}\text { Common ingroup } \\
\text { imagined contact }\end{array}$ & $\begin{array}{c}\text { Standard } \\
\text { imagined contact }\end{array}$ & $\begin{array}{l}\text { Control-common } \\
\text { ingroup identity }\end{array}$ & $\begin{array}{c}\text { Control- } \\
\text { individual } \\
\text { stranger }\end{array}$ \\
\hline Contrast 1 & 1 & -1 & 0 & 0 \\
\hline Contrast 2 & 3 & -1 & -1 & -1 \\
\hline Contrast 3 & 0 & 2 & -1 & -1 \\
\hline Contrast 4 & 0 & 0 & 1 & -1 \\
\hline
\end{tabular}

